\title{
ORIGINAL
}

\section{CALIDAD DEL AGUA DE FUENTES DE MANANTIAL EN LA ZONA BÁSICA DE SALUD DE SIGÜENZA}

Rita Rodríguez García. (1), Carmen Martínez Muñoz (2), Domiciano Hernández Vizcaino (3), Jesús de Lucas Veguillas (3) y $\mathbf{M}^{\mathrm{a}}$ Luisa Acevedo de Pedro (3)

(1) Centro de Salud de Sigüenza. Guadalajara.

(2) Distrito Veteribario Zona de Sigüenza. Guadalajara.

(3) Laboratorio de la Delegación Provincial de la Consejería de Sanidad de la Junta de Comunidades de Castilla La Mancha. Guadalajara.

\section{RESUMEN}

Fundamentos: Las fuentes de manantial tienen un control analítico escaso o inexistente, especialmente las alejadas de los núcleos urbanos, lo que supone un riesgo sanitario por la posibilidad de la presencia en el agua de microorganismos patógenos y sustancias indeseables. El objetivo de este trabajo fue estudiar los factores de riesgo contaminante de los manantiales y determinar la potabilidad del agua de los mismos.

Método: Estudio descriptivo transversal, con investigación de la frecuencia y distribución de los factores de riesgo contaminante según la ubicación urbana o rústica del manantial. Realización de dos controles analíticos, separados seis meses, de los parámetros fisidos controles analíticos, separados seis meses, de los parámetros fisidel agua de 38 fuentes incluidas.

Resultados: Los factores de riesgo contaminantes más frecuentes fueron: en fuentes urbanas pastoreo $(53,8 \%)$, maleza $(53,8 \%)$ y cruce con aguas residuales $(53,8 \%)$; en rústicas pastoreo( $72 \%)$, maleza (32\%) y escorrentías(32\%). Fueron potables en el primer control el 53,8\% de fuentes urbanas y $60 \%$ de rústicas; en el segundo el $76,9 \%$ y $68 \%$ respectivamente. Sólo el $47,4 \%$ del total fueron potables en los dos controles. La contaminación microbiológica apareció en el 44,7\% de manantiales y la físico-química en el 13,1\%.

Conclusiones: Los factores de riesgo contaminante pueden afectar un manantial ante la falta de protección suficiente, y su estudio proporcionará claves sobre la posibilidad y procedencia de la contaminación. Al realizar dos controles analíticos se produce una disminución del porcentaje de fuentes potables, lo que revela el riesgo y susceptibilidad de estos abastecimientos y la necesidad e importancia de controles sanitarios periódicos.

Palabras clave: Calidad del agua. Contaminación ambiental. Factor de riesgo.

Correspondencia:

Rita Rodríguez García

Centro de Salud de Sigüenza

Carretera de Madrid $\mathrm{N}^{\circ} 3$

19250 Sigüenza

Guadalajara
ABSTRACT

\section{Quality of the Spring Fountain Water in the Basic Healthcare Area of Sigüenza, Spain}

Background: Spring fountains undergo few or no analytical checks, especially those located far away from centers of population, which poses a health risk due to the possibility of disease-causing microorganisms and undesirable substances being in the water. This study is aimed at studying the spring contamination risk factors and determining the spring fountain water fitness for drinking.

Method: A cross-sectional, descriptive study, with investigation of the frequency and spread of the contamination risk factors depending upon the developed or undeveloped location of the spring. Two analytical checks, conducted six months apart, of the physicochemical and microbiological parameters selected for assessing the fitness for drinking of the water of 38 fountains included in the study.

Results: The most frequent contamination risk factors were: for fountains located in developed areas, grazing $(53.8 \%)$, weeds $(53.8 \%)$ and crossing wastewater (53.8\%); for those located in undeveloped areas, grazing $(72 \%)$, weeds $(32 \%)$ and falling debris $(32 \%)$ A total of $53.8 \%$ of the fountains located in developed areas and $60 \%$ of those in undeveloped areas were found fit for drinking in the first test; $76.9 \%$ and $68 \%$ having respectively been found fit in the second test. Solely $47.4 \%$ of the total were found fit for drinking in both of test. Solely $47.4 \%$ of the total were found fit for drinking in both of
the tests. Microbiological contamination was found in $44.7 \%$ of the springs, and the physicochemical contamination in $13.1 \%$.

Conclusions: The contamination risk factors can have a bearing on a spring when sufficient protection is lacking, and the study thereof will provide keys as to the possibility and source of the contamination. When two analytical checks were made, there was a decrease in the percentage of fountains having water fit for drinking, which reveals the risk and susceptibility of these water supplies and the need and importance of regular health department checks. tor. 


\section{INTRODUCCIÓN}

Los manantiales son aguas subterráneas que debido a la orografía del terreno emergen a la superficie, generalmente en laderas o llanuras, al encontrar las corrientes capas impermeables en los suelos por los que discurren. El agua que se encuentra en la naturaleza no es pura, a través de su paso por el suelo se carga de minerales que le darán sus características peculiares, pero también puede recoger materia orgánica, gases o microorganismos. Tradicionalmente la población asocia el agua de manantial con buena calidad, confiando que el proceso de depuración natural, al filtrarse por distintas capas freáticas, elimine las sustancias no deseadas. Las fuentes constituyen para muchas personas una alternativa a la red pública de abastecimiento, ante alteraciones en el suministro, excursiones, paseos, o porque tradicionalmente se le asocien unas propiedades específicas. Si bien la legislación establece la periodicidad de controles sobre las fuentes públicas ${ }^{1}$, éstos sólo se realizan en la mayoría de los casos en las que se localizan dentro del municipio, quedando las situadas en el campo sin control sanitario. Tampoco se aplican medidas oficiales de protección de los manantiales, por lo que éstos únicamente cuentan con los cuidados de algunos ayuntamientos, asociaciones de ganaderos y usuarios que realizan labores de limpieza y mantenimiento.

En la calidad de las aguas o en su contaminación contribuyen especialmente factores que intervienen en diversas fases del abastecimiento y que en el caso de las fuentes se refieren a la captación y conducción ${ }^{2}$. Estos factores de riesgo contaminante (FRC), sin ser directamente responsables de la contaminación, contribuyen con su presencia al aumento de la probabilidad de que aparezca dicha contaminación, pudiendo afectar tanto a parámetros físico-químicos como microbiológicos, modificándolos y dando lugar a la falta de potabilidad del agua $^{3}$. Algunos de estos factores pueden ser: presencia cercana de excretas humanas y/o animales de sangre caliente, animales vivos en la corriente, rebosamiento de aguas residuales, escorrentías, presencia de fisuras, empleo de material inadecuado en la construcción, filtraciones a través del suelo, maleza, vertederos, impregnación del suelo por sustancias tóxicas naturales o procedentes de vertidos de la agricultura o industria etc. Tiene enorme importancia la calidad del terreno, ya que los arenosos suelen dar aguas menos contaminadas por procesos de filtración, mientras los arcillosos, al ser impermeables, no producen este efecto, y el agua pasa a través de grietas ${ }^{4}$.

El control de la potabilidad y calidad es sumamente importante si se tiene en cuenta que el agua es un importante vehículo de transmisión de enfermedades por contaminación microbiológica producida por patógenos intestinales: bacterias, virus, protozoos, helmintos; o por contaminación fisicoquímica debido a la aparición de sustancias no deseables o que siendo elementos de la composición habitual del agua superan la Concentración Máxima Admisible (CMA), ya sean de procedencia natural o artificial $^{5}$. Revisiones de algunos trabajos sobre potabi$\operatorname{lidad}^{6,7}$ en pozos y fuentes de manantial revelan que en el $60 \%$ de los pozos y el $30 \%$ de las fuentes se detecta contaminación bacteriana de origen fecal.

El objetivo de este estudio fue: 1) Detectar y analizar los FRC relacionados con los manantiales según la ubicación de la fuente, ya sea urbana o rural. 2) Evaluar la potabilidad del agua según los criterios establecidos por la legislación para el agua de los abastecimientos públicos y estudiar la variación de la potabilidad en dos periodos estacionales distintos.

\section{MATERIAL Y MÉTODOS}

Ámbito del estudio: Se trata de un estudio descriptivo transversal, realizado entre 
junio de 2001 y febrero de 2002; el ámbito geográfico se centra en las localidades comprendidas en la Zona Básica de Salud (ZBS) de Sigüenza, que abarca una extensión de $631,48 \mathrm{Km}^{2}$, con un censo de población de 5.821 habitantes, lo que supone una densidad de población de 9,22hab $/ \mathrm{km}^{2}$. En los suelos predominan los conglomerados y areniscas del Triásico Inferior y los manantiales se localizan generalmente en los lugares de contacto entre las calizas permeables del Jurásico Inferior y las rocas impermeables (yesos y arcillas del Keuper). La altitud media es de 1.000 metros y la pluviometría anual no suele superar los $600 \mathrm{~mm}^{8}$.

Identificación de los manantiales: Se realizó el censo de las fuentes de manantial no conectadas a la red pública de abastecimiento mediante entrevista personal con algunos vecinos de los municipios de la ZBS de Sigüenza. Se incluyeron en el estudio 38, en las que se recogía agua habitualmente o eran susceptibles de frecuentarse. Se procedió a su localización cartográfica en mapas de escala 1/50.000 del Servicio Geográfico del Ejército ${ }^{9-11}$ y más tarde a la localización sobre el terreno.

Datos analizados: Se recogieron y analizaron los siguientes datos sobre el manantial:

- Estructurales: Estado de la construcción, material empleado en la conducción y presencia de arquetas en la misma, alteraciones de la permeabilidad o grietas en alguna de las fases del abastecimiento y aliviaderos sin protección.

- Ambientales: Cercanía de pozos negros o cruces con aguas residuales, escorrentías o estancamiento de aguas, existencia de núcleos zoológicos, explotaciones ganaderas, industrias, tipo de agricultura, maleza, pastoreo y abrevaderos dependientes de la fuente.

Se clasificaron los manantiales según la situación de la fuente, ya fuera urbana o rús- tica. El resultado fue de 13 manantiales urbanos (la fuente se hallaba dentro del municipio y la captación procedía del mismo, o del exterior) y 25 manantiales eran totalmente rústicos (la fuente y el manantial se encontraban en el campo). De cada fuente se realizaron dos tomas de muestras, separadas seis meses, la primera en primaveraverano del 2001 y la segunda en el otoñoinvierno de 2001-2002. Al no tratarse de exámenes oficiales se estableció en el estudio dicho periodo como margen de tiempo que permitiera detectar un cambio en la calidad del agua en dos estaciones del año con climatología diferente. El agua se recogió directamente sin adoptar medidas especiales, en recipientes estériles de $2.000 \mathrm{ml}$, suministrados por el laboratorio de la Delegación Provincial de Sanidad de Guadalajara, manteniendo las muestras refrigeradas a $4^{\circ} \mathrm{C}$ hasta el momento de procesarlas en el laboratorio, no transcurriendo más de 24 horas hasta dicho momento.

La calidad del agua se evalúo conforme a la legislación vigente para abastecimiento y control del agua potable ${ }^{1,12,13}$. Los parámetros analizados fueron:

- Características organolépticas: Se observó subjetivamente la ausencia de olor y color, excluyendo el sabor por ser aguas no tratadas y suponer un riesgo para el examinador.

- Parámetros físico-químicos: Turbidez, conductividad, $\mathrm{pH}$, calcio, nitritos, nitratos, amonio, oxidabilidad al permanganato, flúor, dureza total y magnesio.

- Parámetros microbiológicos: Bacterias aerobias (BA) a $22^{\circ} \mathrm{C}$ y $37^{\circ} \mathrm{C}$, coliformes totales (CT), coliformes fecales (CF), estreptococos fecales (SF), y clostridios sulfito reductores (CSR).

Se consideró agua potable la que no superaba la Concentración Máxima Admisible 
en los parámetros citados. El método analítico utilizado para el control de los parámetros citados fue el establecido por la legislación vigente para el control del agua de consumo público $^{14,15}$.

\section{RESULTADOS}

La distribución de la frecuencia de los FRC (tabla 1), relacionados con cada abastecimiento muestra la diferencia según la ubicación de la fuente, siendo en las urbanas los más frecuentes: pastoreo, maleza y cruce con aguas residuales o pozos negros, presentes cada uno de ellos en el 53,8 \%. En los abastecimientos rústicos el más frecuente fue el pastoreo $(72 \%)$, maleza (32\%) y escorrentías o estancamientos de aguas $(32 \%)$.

Del total de las fuentes analizadas en el estudio el $89,6 \%$ presentaban entre 1 y 4
FRC, el 7,8\% entre 5 y 8 , y sólo un $2,6 \%$ no presentaba ninguno. En dos fuentes se detectó en el segundo control que los factores estructurales habían cambiado drásticamente: en una mejoraron, haciéndolo también la calidad del agua y en la otra se había deteriorado en gran manera la construcción y la captación, apareciendo un alto nivel de contaminación bacteriana fecal que no apareció en el primer análisis realizado.

En el primer control, superaron los criterios de potabilidad el $53,8 \%$ de las fuentes urbanas y el $60 \%$ de las fuentes rústicas. Superaron el segundo control el 76,9\% de las primeras y el $68 \%$ de las segundas (figura 1 ). $\mathrm{El}$ total de fuentes que superaron el primer control fue de $57,9 \%$ y el segundo de $71 \%$. La variación de potabilidad entre los dos controles se localizó en el 34,3\% de las fuentes, al detectarse contaminación en un solo control, frente al $18,3 \%$ que resultaron no pota-

Tabla 1

Distribución de la frecuencia de aparición de los FRC según localización de la fuente

\begin{tabular}{|c|c|c|c|c|c|c|}
\hline \multirow{3}{*}{$\begin{array}{l}\text { Factores de Riesgo Contaminante } \\
\text { Zona de pastoreo }\end{array}$} & \multicolumn{2}{|c|}{$\begin{array}{c}\text { Fincas } \\
\text { Urbanas }\end{array}$} & \multicolumn{2}{|c|}{ Fincas Rústicas } & \multicolumn{2}{|c|}{ Total } \\
\hline & \multicolumn{2}{|c|}{ Número $\quad \%$} & \multicolumn{2}{|c|}{ Número $\%$} & \multicolumn{2}{|c|}{ Número $\%$} \\
\hline & 7 & 53,8 & 18 & 72 & 25 & 65,7 \\
\hline Maleza & 7 & 53,8 & 8 & 32 & 15 & 39,4 \\
\hline Agricultura extensiva & 2 & 15,3 & 7 & 28 & 9 & 23,6 \\
\hline Escorrentías o estancamientos & 1 & 7,6 & 8 & 32 & 9 & 23,6 \\
\hline Explotaciones ganaderas & 1 & 7,6 & 7 & 28 & 8 & 21 \\
\hline Cruces con aguas residuales & 7 & 53,8 & - & - & 7 & 18,4 \\
\hline Abrevaderos & - & - & 6 & 24 & 6 & 15,7 \\
\hline Agricultura intensiva & & & 4 & 16 & 6 & 15,7 \\
\hline Defectos estructurales en captación & - & - & 5 & 20 & 5 & 13,1 \\
\hline Existencia arquetas conducción & 2 & 15,3 & 1 & 4 & 3 & 7,8 \\
\hline Basureros o vertederos próximos & 1 & 7,6 & 1 & 4 & 2 & 5,2 \\
\hline Material inadecuado construcción & 1 & 7,6 & 1 & 4 & 2 & 5,2 \\
\hline Aliviaderos sin protección & - & - & 1 & 4 & 1 & 2.6 \\
\hline Núcleos zoológicos próximos & - & - & 1 & 4 & 1 & 2.6 \\
\hline
\end{tabular}


Figura 1

Distribución de las fuentes potables en los dos periodos del estudio según su ubicación

国 Urbanas $\square$ Rústicas $\square$ Total

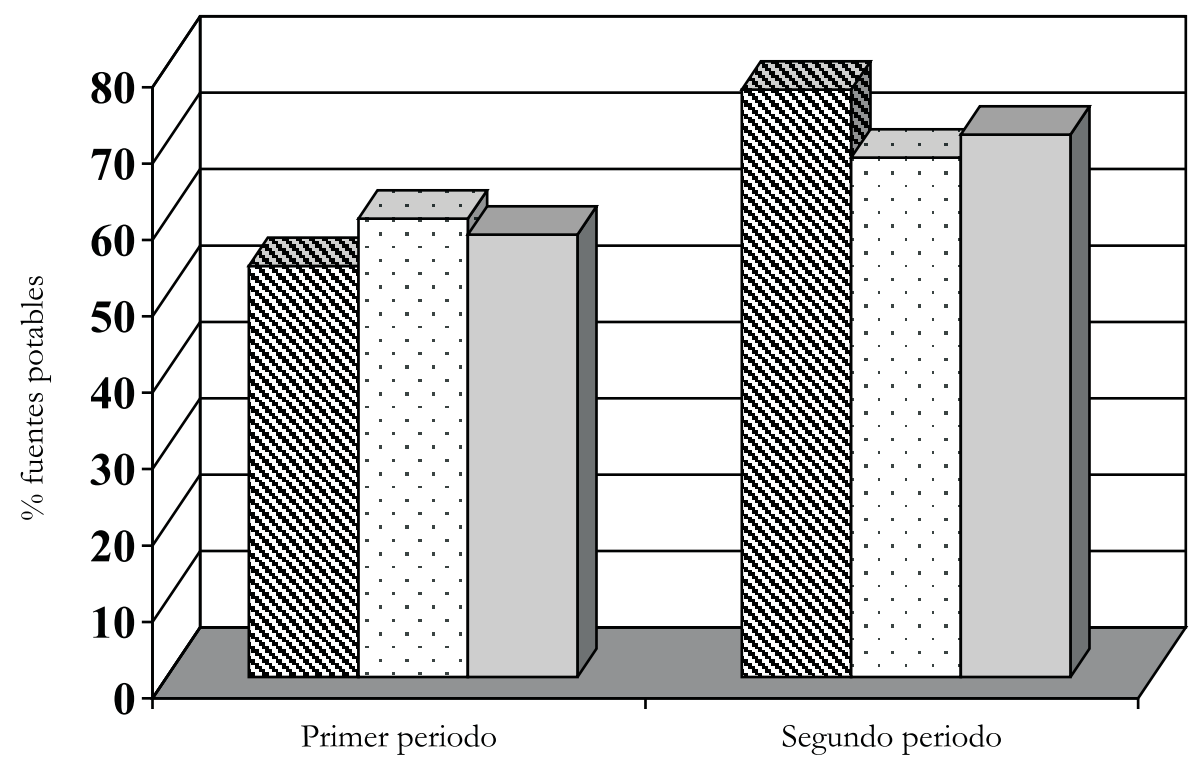

Figura 2

Calificación sanitaria de las fuentes durante los dos periodos del estudio

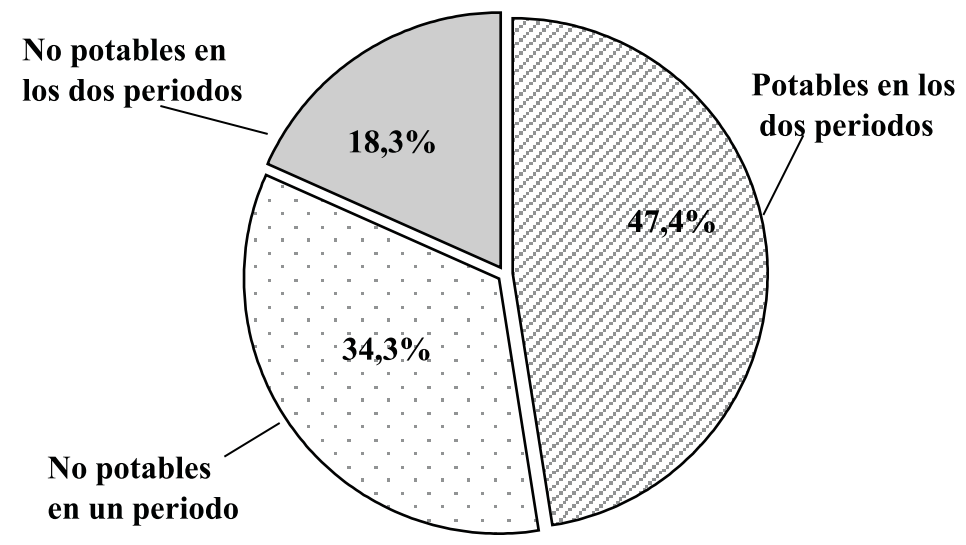

bles en los dos exámenes realizados (figura 2), siendo detectada en éstas últimas la contaminación más importante, tanto cualitativa y cuantitativamente. Sólo el 47,4\% de las fuen- tes pudo cumplir los criterios de potabilidad en los dos controles realizados. No observó subjetivamente ninguna alteración de las características organolépticas (olor y color). 
Figura 3

Alteraciones de los parámetros en los dos periodos del estudio

国1er control $\mathrm{Q}$ 2do control $\square$ Total

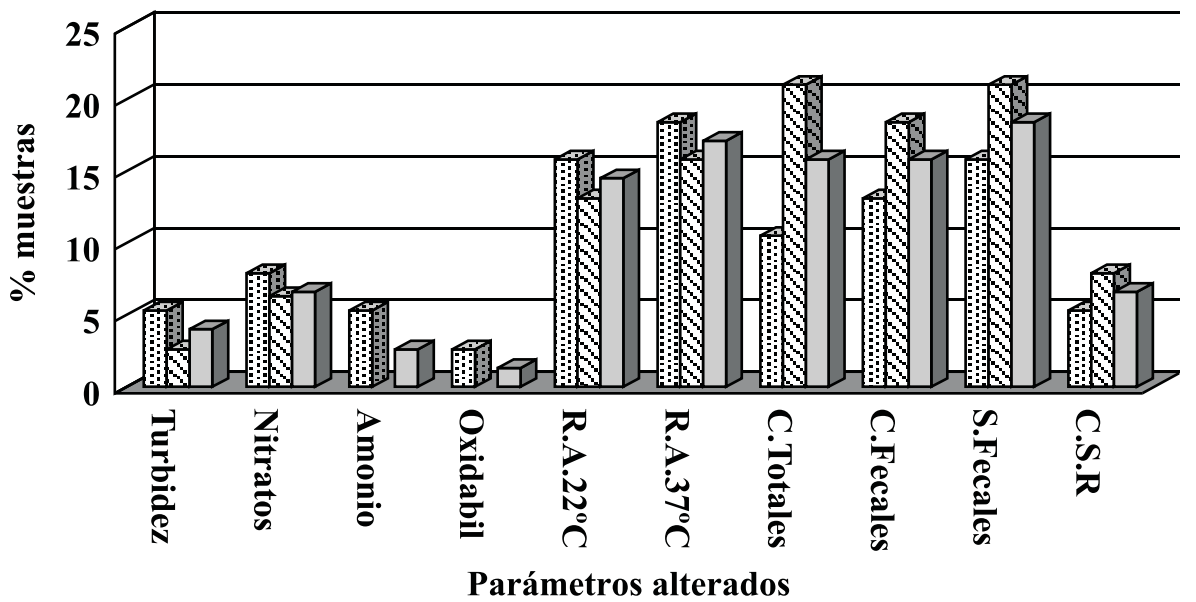

Las alteraciones microbiológicas afectaron al 44,7\% de los manantiales y las alteraciones físico-químicas al $13,1 \%$. La distribución en los dos periodos del estudio (figura 3), fue: la turbidez resultó alterada en tres muestras (4\%), el amonio en dos mues$\operatorname{tras}(2,6 \%)$ y la oxidabilidad en una muestra $(1,3 \%)$, y los nitratos en cinco muestras $(6,6 \%)$. Los niveles de $\mathrm{pH}$, calcio, dureza total, magnesio, conductividad, y nitritos cumplieron la normativa establecida en todos los casos. Todos los manantiales contenían flúor, aunque los niveles por lo general no superaron los $0,3 \mathrm{mg} / \mathrm{l}$, exceptuando una fuente rica en sales minerales que presentó una cifra de $0,6 \mathrm{mg} / \mathrm{l}$.

Los parámetros microbiológicos fueron los principales responsables de la falta de potabilidad del agua. En los 76 exámenes realizados (dos cada fuente), el recuento de Aerobias a $22^{\circ} \mathrm{C}$ superaba las $100 \mathrm{ufc} / \mathrm{ml}$ (unidades formadoras de colonias $/ \mathrm{ml}$ ) en 11 muestras $(14,5 \%)$, las Aerobias a $37^{\circ} \mathrm{C}$ supe-

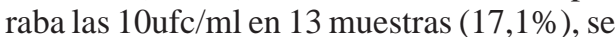
detectaron Coliformes Totales (ufc/100ml) en 12 muestras(15,8\%), Coliformes Fecales (ufc/100ml) en 12 muestras(15,8\%), Estreptococos Fecales (ufc/100 ml) en 14 muestras $(18,4 \%)$ y Clostridios Sulfito Reductores en cinco muestras $(6,6 \%)$.

\section{DISCUSIÓN}

Con este estudio se obtiene una visión global del estado de las fuentes de manantial de la ZBS de Sigüenza. Aunque el número de fuentes objeto de investigación es reducido, si se encuentran representados los distintos modelos que se pueden encontrar en la zona. La falta de conocimientos geológicos limitó un posible estudio de los tipos de suelo, condicionantes topográficos, permeabilidad, grietas, fallas, corrientes subterráneas que podrían considerarse como factores de riesgo por la posibilidad de influir en la contaminación de un manantial. También se encontró dificultad en algunos casos para recoger datos sobre características de los abastecimientos por encontrarse en lugares poco accesibles las captaciones, o ser tan 
antiguas que era imposible conocer su estructura, lugar exacto o materiales empleados; no obstante se considera que los datos aportados sobre los FRC como el número de parámetros que se incluyen para el estudio de la potabilidad son suficientes para dar suficiente validez interna al estudio.

La detección y control de los FRC relacionados con los manantiales es muy importante, ya que nos puede orientar sobre la posible causa de la contaminación. Estos factores aparecieron en 37 de las 38 fuentes objeto de estudio, y se advirtió que es posible que se necesite la asociación de varios de ellos (estructurales y medioambientales) para facilitar la contaminación. Se produce una coincidencia en los FRC que aparecen con más frecuencia en los dos tipos de abastecimiento, sin duda debido a que los abastecimientos clasificados como urbanos se encontraban en núcleos rurales pequeños (menores de 100 habitantes), y por tanto con similares características a los manantiales clasificados como rústicos:

- El pastoreo fue el FRC más frecuente en los dos tipos de abastecimiento, al encontrarse su captación en zonas de pastos de ganado lanar. En algunos casos estos manantiales abastecen abrevaderos contiguos lo que da lugar a un tránsito directo y continuo por sus inmediaciones de los rebaños y también de otros animales que acuden de núcleos zoológicos o explotaciones ganaderas próximas, dejando sobre el suelo gran cantidad de heces que pueden llegar a la captación por defectos estructurales como grietas, arquetas no cubiertas etc.

- La presencia de maleza próxima al manantial (hierba alta, matorral, zarzas, espinos, etc) supuso un riesgo por sí misma ya que la descomposición de la materia orgánica (restos vegetales) puede filtrarse a través del suelo alterando parámetros como la oxidabili- dad, turbidez, amonio, nitritos o nitratos. También una espesa maraña vegetal facilita la presencia de pájaros y roedores que nidifican o establecen allí sus madrigueras dando lugar a una posible contaminación por la filtración de sus excretas, o por la penetración en el caso de los roedores a la corriente de agua a través de aliviaderos no protegidos o tuberías de desagüe demasiado grandes.

- Las arquetas tienen como finalidad hacer posible la limpieza y el control de las conducciones pero en algunos casos se han convertido en un grave riesgo al permanecer sin mantenimiento y deterioradas permitiendo así el crecimiento de algas, acumulación de suciedad y la presencia de animales en la corriente.

- En los abastecimientos rústicos se encontraron escorrentías próximas a los abastecimientos procedentes de agua de lluvia o de otros cauces, así como estancamientos de aguas a pocos metros que supone un peligro de contaminación similar al que se produce en los abastecimientos urbanos con la cercanía de cruces de aguas residuales o depósitos de materia orgánica (corrales, vertederos de estiércol etc) ya que en muchos casos las tuberías de conducción de agua están en niveles inferiores a los mismos.

- En las zonas de cultivo extensivo o intensivo los manantiales recogen las filtraciones que provienen del agua de lluvia o del regadío y que pueden arrastrar contaminación derivada de sustancias orgánicas (purines, estiércol) o de sustancias químicas (fertilizantes, pesticidas etc) dando lugar a un grave problema, que en la mayoría de los casos era desconocido por la población.

Los porcentajes de fuentes contaminadas serían similares a trabajos publicados sobre 
potabilidad $^{6,7}$, si sólo se tuviera en cuenta un control. Al realizar dos controles la proporción de fuentes que superan los criterios de potabilidad baja de forma importante, siendo los parámetros microbiológicos los que en una gran parte fueron responsables de la falta de potabilidad. Debemos tener en cuenta que nuestro estudio se desarrolla en una zona rural no industrializada, donde prácticamente los únicos vertidos que podemos encontrarnos son los que provienen de la agricultura y ganadería. Aún así, cinco fuentes (13.1\%) tuvieron alteraciones de los parámetros físico-químicos. La diferencia de potabilidad según la localización urbana o rústica fue poco relevante. En el segundo control (otoño-invierno) se halló en varias fuentes mayor diversidad y concentración de microorganismos al realizar la recogida de la muestra tras un periodo de lluvias abundantes, lo cual sugiere la posibilidad de que las precipitaciones puedan aumentar el arrastre y filtrado rápido de sustancias químicas y microorganismos por los suelos; esta circunstancia podría explicar la paradoja del segundo control, donde hubo más proporción de fuentes potables; sin embargo, las que resultaron contaminadas, tenían un nivel de contaminación mayor.

Las alteraciones de la oxidabilidad, turbidez y amonio se produjeron en los dos únicos manantiales que se encuentran dentro una extensa zona de pinar, con gran cantidad de materia vegetal en descomposición, dependientes de acuíferos muy superficiales, con aguas poco mineralizadas cuyo caudal es dependiente de la pluviometría estacional. Este resultado nos advierte sobre la importancia de cuidar y proteger los manantiales evitando maleza cuya descomposición, al filtrarse por suelos muy porosos, altere la calidad del agua. De las tres fuentes donde el nivel de nitratos superó la Concentración Máxima Admisible(CMA), dos de ellas se encontraban en amplias zonas dedicadas al cultivo, que sugiere como origen el abono periódico ${ }^{16,17}$ con fertilizantes nitrogenados o susceptibles de originar nitratos; la tercera fuente provenía de una captación próxima a un encerradero de ganado lanar y un vertedero de estiércol que hizo suponer como causa contaminante la degradación de la materia orgánica ya que en niveles superiores no se observó otros factores de riesgo que pudieran justificar este problema. En todos los casos se informó al Ayuntamiento correspondiente de la falta de potabilidad del agua y del riesgo que puede acarrear su consumo para la salud humana y animal ${ }^{18}$.

Todas las aguas contenían flúor, aunque los niveles por lo general no superaron los $0,3 \mathrm{mg} / \mathrm{l}$, que se considera bajo como preventivo en la incidencia de caries dental ${ }^{19,20}$, aunque sí son superiores a los que tienen las redes públicas de abastecimiento que se proveen de aguas superficiales. Sólo un manantial rico en sales minerales presentó una media de 0,6mg/l. Fueron detectadas diferencias apreciables en el nivel de flúor entre manantiales muy próximos, pero dada la ausencia de vertederos industriales esta variación puede deberse a la composición del suelo por donde discurren las aguas.

El recuento de aerobias a $22^{\circ} \mathrm{C}$ y $37^{\circ} \mathrm{C}$ no se tuvo en cuenta para la clasificación de la potabilidad, pero sí como orientador de calidad; sólo superó las 500 unidades formadoras de colonias (ufc) en cuatro controles y en el resto se mantuvieron en un nivel aceptable. Aunque la legislación sólo establece un nivel guía ${ }^{1}$, su uso como indicador de calidad del agua es importante ${ }^{21}$ ya que puede ser el primer signo de alarma ante una nueva contaminación, proliferación de algas, suciedad o deterioro de alguna fase del abastecimiento que indicaría la necesidad de tomar medidas de control. La presencia aislada de Coliformes Totales (CT), detectada en dos casos, pueden sugerir algún tipo de contaminación no fecal, ya que no son específicos de ésta ${ }^{7,22}$ pudiendo provenir del suelo, algas etc. y se debe estar alerta ante la posibilidad de que aparezcan otros tipos de gérmenes. En los niveles de Coliformes Fecales (CF) y Estreptococos Fecales (SF) 
no se obtuvo suficiente concentración de microorganismos para establecer la relación $\mathrm{CF} / \mathrm{SF}$ que según algunos autores ${ }^{23}$ orientaría sobre la procedencia humana de la contaminación si el resultado es igual o mayor de 4 y procedencia animal si es igual o menor de 0,7 ; pero se puede establecer con bastante fiabilidad la procedencia de la contaminación con el estudio individualizado de los Factores de Riesgo, resultando en la mayoría de los casos de procedencia animal relacionada con el pastoreo, vertederos de explotaciones ganaderas, presencia de animales, (roedores, pájaros), entre la maleza adyacente o dentro de las arquetas en las conducciones. Sólo en uno de los casos la contaminación estaba relacionada con cruces de aguas residuales y una conducción urbana antigua realizada con material poroso. La presencia de Clostridios Sulfito Reductores (CSR) persistió en las dos fases del estudio en dos manantiales, unas veces asociada a otros gérmenes fecales y otras aisladamente como único indicador, lo que puede indicar una contaminación antigua o producida a distancia del foco detectado. Su uso sistemático como indicador puede ser muy útil sobre todo cuando los controles no se realizan con la frecuencia deseable, ya que el resto de gérmenes estudiados tienen una corta supervivencia $^{24}$.

Los parámetros microbiológicos utilizados son aceptados por la comunidad científica internacional como buenos indicadores, ya que ofrecen la prueba más sensible para evaluar la calidad sanitaria del agua. Su presencia indica la posibilidad de que también estén presentes otros organismos fecales (virus, protozoos, etc.), y al contrario su ausencia también orientará sobre la posible ausencia de otros organismos de contaminación fecal, si bien siempre habrá que tener en cuenta la mayor supervivencia de los virus a los factores ambientales.

Con este estudio se ha comprobado la diferencia en calidad y composición del agua de manantiales muy próximos y lo sus- ceptibles que pueden ser a la contaminación cuando la protección es insuficiente. Hay que señalar que los manantiales que superaron los criterios de potabilidad en los dos controles poseían una gran calidad en todos los parámetros.

Se insta a las Administraciones competentes a elaborar y articular mecanismos para proteger estos pequeños manantiales que son parte importante del patrimonio natural heredado de nuestros mayores.

\section{AGRADECIMIENTOS}

A la Delegación Provincial de la Consejería de Sanidad de Guadalajara y personal de laboratorio de la misma, sin cuya colaboración no hubiera sido posible este estudio; y a $\mathrm{D}^{\mathrm{a}} \mathrm{M}^{\mathrm{a}}$ Antonia García Garralón que realizó el traslado de las muestras hasta Guadalajara.

\section{BIBLIOGRAFÍA}

1. Boletín Oficial del Estado. Real Decreto 1138/1990 de 14 de Septiembre, por el que se aprueba la Reglamentación Técnico Sanitaria para el abastecimiento y el control de calidad de las aguas potables de consumo público. BOE núm 226,20/9/1990.

2. Soengas JA, González Carballo M, San Miguel A, López R, Gonda Copa A. Epidemiología Hídrica y Análisis de Aguas. Salud Rural 1997; 7:23-30.

3. Organización Panamericana de Salud. Metodología de identificación y evaluación de riesgo de sitios contaminados [citado 24 de junio de 2001]. Disponible en: www.cepis.ops.oms.org/eswww/ fulltext/gtz/metoiden/metcap03/html.

4. Fernández-Crehuet Navajas J, Pérez López JA. Servicio de abastecimiento de aguas. En: Piédrola Gil G, Domínguez Carmona M, Cortina Creús P, Gálvez Vargas R, Sierra López A, Sáenz González MC, et al. Medicina Preventiva y Salud Pública. 8 ad. Barcelona: Salvat Editores;1989. p. 168-77.

5. Fernández-Crehuet Navajas J, Pérez López JA. El agua como factor higiénico Piédrola Gil G, Domínguez Carmona M, Cortina Creús P, Gálvez Vargas 
R, Sierra López A, Sáenz González MC, et al. Medicina Preventiva y Salud Pública. $8^{\text {a }}$.Ed. Barcelona: Salvat Editores;1989. p. 157-67.

6. Combarro MP, Longo E, Agrelo D, Arias C, Pardo F, Villa TG, Garrido MJ. Contaminación bacteriana en pozos de zonas rurales de Galicia. Rev Sanid Hig Pública 1988; 62:1561-9.

7. Alvarez Seoane G. Calidad del agua de fuentes públicas y pozos particulares, con especial referencia al Término de Vigo. Dictámenes oficiales. Rev San Hig Publica 1988; 62:1303-16.

8. Servicio de Publicaciones de la Junta de Comunidades de Castilla La Mancha. Guía de Castilla La Mancha «Espacios Naturales». Toledo: Servicio de Publicaciones de la Junta de Comunidades de Castilla La Mancha;1991. p.165-76.

9. Barahona. Mapa 434. Escala 1/50.000. Servicio Geográfico del Ejército. Año 1973. 2a edición; 1981.

10. Sigüenza. Mapa 461. Escala 1/50.000. Servicio Geográfico del Ejército. Año 1973. $3^{\text {a }}$ edición; 1990

11. Ledanca. Mapa 487. Escala 1.50.000.Servicio Geográfico del Ejército. Año 1974. 2ª edición; 1980.

12. Diario Oficial de las Comunidades Europeas. Directiva 80 / 777 / CEE del Consejo de 15 de julio de 1980 relativa a la aproximación de las legislaciones de los Estados Miembros sobre explotación y comercialización de las aguas minerales naturales. DOCE núm L229, 30/8/1980.

13. Diario Oficial de las Comunidades Europeas Directiva 98/83/CE del Consejo de 3 de Noviembre de 1998 relativa a la calidad de las aguas destinadas al consumo humano. DOCE núm L330, 5/12/1998.

14. Boletín Oficial del Estado. Orden de 1 de Julio de 1987 por la que se aprueban los métodos oficiales de análisis físico-químicos de aguas potables de consumo público. BOE núm 163, 9/7/1987.

15. Boletín Oficial del Estado. Orden de 27 de Julio de 1983, por la que se establecen los métodos oficiales de análisis microbiológicos de aguas potables de consumo público. BOE núm 193, 13/8/1983.

16. Ministerio de Sanidad y Consumo. «Guía para la elaboración del Programa del Medio en Atención Primaria de Salud. Madrid: Ministerio de Sanidad y Consumo; 1985.

17. Costell M, La Orden A. Programa de vigilancia de nitratos en aguas de consumo público en la Comunidad Valenciana. Actas de las Primeras Jornadas Nacionales de Sanidad Ambiental para Comunidades Autónomas;1989 Sep 29-30:Talavera de la Reina. Toledo: Servicio de Publicaciones de la Junta de Castilla La Mancha; 1989.

18. Llopis A, Morales MM, Rodríguez R, Haro M. Presencia de nitratos en las aguas de consumo público como factor de riesgo sobre la mortalidad por tumor maligno de estómago. Actas de las Primeras Jornadas Nacionales de Sanidad ambiental para comunidades Autónomas;1989 Sep 29-30: Talavera de la Reina. Toledo: Servicio de Publicaciones de la Junta de Comunidades de Castilla La Mancha; 1989 .

19. OMS. Etiología y prevención de la caries dental. Serie Informes Técnicos 1972; 4492:521.

20. Llopis A, Morales MM, Fernando T, Haro M, Zurriaga O, Cortina P. Niveles de flúor en las aguas de consumo público de la provincia de Valencia. Rev San Hig Pública 1989; 63:35-40.

21. Lamka KG, Le Chevalier MW, Seidler RJ. Bacterial contamination of drinking water supplies in modern rural neighborhood. Appl Environ Microbiol 1980; 39:734-8

22. Geldreich EE, Kenner BA and Kabler PW. Occurrence of coliforms fecal coliforms, al fecal streptococci on vegetacion and insects. Appl Microbiol $1964 ; 12: 63-9$.

23. Geldreich EE and Kenner BA. Concepts of fecal streptococci in stream pollution. J Water Pollut 1969. Control Fed: R336-R352

24. Organización Panamericana de Salud. «Guías para la calidad del Agua Potable. Volumen 2, Criterios relativos a la salud y otra información base». Publicación Científica Nº506. Washington DC: OPS; 1987. 